Carla Ribeiro Volpini Silva ${ }^{1,2}$

Mariana Ribeiro Volpini Lana ${ }^{3}$

Thaís Cláudia D’Afonseca da Silva ${ }^{4,5}$

\title{
O TRABALHO DO MARRETEIRO NAS INDÚSTRIAS DE FUNDIÇÃO: ATIVIDADE EM CONDIÇÕES NOCIVAS À SAÚDE E INCOMPATÍVEL COM O DIREITO BRASILEIRO
}

The sledgehammer work on foundry industries: an activity on harmful conditions to the health and incompatible with the Brazilian law

${ }^{1}$ Faculdade de Direito, Universidade Federal de Minas Gerais. Belo Horizonte/MG, Brasil. ${ }^{2}$ Universidade de Itaúna. Itaúna/MG, Brasil.

${ }^{3}$ Faculdade Estácio de Sá. Belo Horizonte/MG, Brasil.

${ }^{4}$ Escola Superior Dom Helder Câmara. Belo Horizonte/MG, Brasil.

${ }^{5}$ Pontifícia Universidade Católica de Minas Gerais. Belo Horizonte/MG, Brasil.

Correspondência: Carla Ribeiro Volpini Silva. E-mail: carlavolpini@hotmail.com.

Recebido em: 06/12/2012. Revisado em: 19/04/2013. Aprovado em: 16.05.2013. 


\section{RESUMO}

O presente artigo tem como escopo demonstrar o trabalho em condições de sofrimento dos trabalhadores marreteiros e em afronta aos princípios da dignidade da pessoa humana e valor social do trabalho. O estudo aponta a necessidade de eliminar esse modelo primitivo de trabalho, com substituição dos instrumentos causadores dos desgastes por martelos pneumáticos, o que minimizaria ou até eliminaria o adoecimento dos trabalhadores. A utilização de marreta, instrumento arcaico, gera grave desgaste físico e psicológico ao trabalhador. O tema foi abordado de uma perspectiva interdisciplinar, incluindo a observação do impacto na saúde do trabalhador e os instrumentos jurídicos que respaldam a eliminação de trabalho degradante e em afronta à dignidade da pessoa humana. A metodologia é a de análise bibliográfica em torno do tema e conclui-se que o severo desgaste à saúde do trabalhador, encontra repúdio no texto constitucional, bem como na normatização da Organização Internacional do Trabalho.

\section{Palavras-chave}

Dignidade da Pessoa Humana; Marreteiro; Meio Ambiente do Trabalho; Trabalho Subumano; Valor Social do Trabalho.

\section{ABSTRACT}

This article aims to demonstrate the work in conditions of suffering by workers who use the sledgehammer which is opposite to the principles of the human dignity and the social value of work. The study points the need of eliminating this primitive model of work, replacing the sledgehammer by pneumatic hammers, which would minimize or even eliminate the illness of workers. The use of the sledgehammer, an archaic instrument, generates serious injury and psychological damage. The approach of the theme is interdisciplinary, including the impact on worker health and the legal instruments that support the elimination of degrading work that affront human dignity. The methodology is based on literature review about the subject. It concludes that the severe wear to worker's health meets repudiation in the constitutional texts, as well as in the standardization of International Labor Organization.

\section{Keywords}

Human Dignity; Sledgehammer Worker; Social Value of Work; Sub Human Work; Workplace Environment. 


\section{Introdução}

A evolução histórica do trabalho humano mostra o predomínio do trabalho em condições de sofrimento, subumano, e penoso sob os princípios técnicos e éticos da ergonomia. O trabalho fisicamente pesado, fator causal de lesões de alta gravidade de membros superiores e da coluna vertebral, muitas vezes incapacitantes, exemplifica o tipo de trabalho de alto risco, que encontra solução na aplicação de novas tecnologias. Modalidades desse tipo de trabalho, que também implica em alto consumo energético, estão sendo substituídas, no setor industrial, por máquinas e instalações mecanizadas ${ }^{1}$.

A lógica do trabalho pode conduzir ao sofrimento do trabalhador, mormente no sistema capitalista, que busca a acumulação acima de tudo, com exploração do trabalho, independentemente das condições físicas e psíquicas desse trabalhador. $\mathrm{O}$ sistema é tão cruel que muitas vezes a utilização das novas tecnologias constitui um dos fatores dos processos de precarização de direitos trabalhistas e que contribuem para maior acumulação; outras vezes, quando convém, são as condições primitivas de trabalho, como no caso debatido, que conduzem ao lucro exacerbado. O modelo de trabalho do marreteiro, desgastante e desumano, talvez seja pior do que se observava nas precárias condições da Revolução Industrial.

Em 2001, segundo a Associação Brasileira de Fundição (ABIFA), o Brasil era o $11^{\circ}$ produtor mundial de fundidos, totalizando quase um milhão e seiscentas mil toneladas por ano, em cerca de mil empresas de pequeno e médio porte, empregando cerca de 40 mil trabalhadores ${ }^{2}$. Em 2008 já se tinha aproximadamente mil e quatrocentos empresas de fundição, sendo, em sua maioria, de capital nacional e de pequeno e médio porte, totalizando cerca de 60 mil trabalhadores empregados e um faturamento de 11 bilhões de dólares, condições que levaram o Brasil a ocupar a sétima posição no ranking mundial de produtores de fundidos naquele $\mathrm{ano}^{3}$.

No entanto, o trabalho do marreteiro ainda é manifestadamente arcaico, penoso e nocivo à saúde, gerador de desconforto físico e psicológico, em grande dissonância com os preceitos legais e morais, apesar de haver alternativa com mais tecnologia para substituição desse trabalho braçal. Assim sendo, de acordo com a Organização Mundial da Saúde (OMS): "Saúde é o estado completo do bem-estar mental e

\footnotetext{
${ }^{1}$ VILARTA, R.; GUTIERREZ, G.L.; CARVALHO, T.H.P.F; GONÇALVES, A (Orgs.). Qualidade de vida e novas tecnologias. Campinas: Ipes Editorial, 2007. 222 p. ANDRADE, Mam; GOSLING, M.; XAVIER, W. S. Por trás do discurso socialmente responsável da siderurgia mineira. Produção, v. 20, n. 3, p. 418-428, 2010.

${ }^{2} \mathrm{CHEGATTI}, \mathrm{S}$. Aplicação de resíduos de fundição em massa asfáltica cerâmica vermelha e fritas cerâmicas. 2004. Dissertação (Mestrado em Engenharia Ambiental) - Universidade Federal de Santa Catarina, Florianópolis, 2004.

${ }^{3}$ FAGUNDES, A. B. Mapeamento do gerenciamento das areias a verde de fundição no Estado do Paraná sob a ótica da produção mais limpa: uma contribuição para o estabelecimento de estratégias. 2010. Dissertação. (Mestrado em Engenharia de Produção) - UTFPR, Ponta Grossa, 2010.
} 
social, e não ausência de doenças e enfermidades" ", concluímos, então, que o excesso de demanda física dessa atividade afeta de forma definitiva a saúde do trabalhador.

O objetivo deste estudo é o de sugerir que modificações sejam realizadas na técnica de trabalho dos marreteiros, a partir da inclusão de tecnologias que reduzem o desgaste físico deles, com base nas premissas da OMS e do direito.

\section{Metodologia}

Para a realização deste trabalho, adotou-se o método de pesquisa monográfico e as técnicas de pesquisa bibliográfica e documental por meio da consulta a diversos documentos, obras e artigos nacionais e internacionais com o objetivo de apresentar as diversas interfaces e posições acerca da temática proposta. Realizou-se ainda pesquisa observacional velada das técnicas de trabalho por meio de vídeos.

\section{Resultados e discussões}

\section{A função do marreteiro e suas consequências nocivas à saúde física e psíquica}

Após coleta e análise das informações pode-se dizer que fundição é o processo pelo qual se obtêm peças com a forma de um molde. A produção de peças fundidas está baseada no aquecimento de um metal até seu estado de fusão e vazamento em moldes contendo areia de moldagem e areia de macharia ${ }^{5}$. A fundição emprega nos seus processos modelos, moldes e machos que promovem às peças fundidas a sua conformação de acordo com as etapas existentes de moldagem, fusão e acabamento ${ }^{6}$. O fornecimento do metal líquido é feito pela alimentação do molde por meio de um sistema de canais nele. Os canais de alimentação alargados ou massalotes permitem que o metal escorra para a cavidade do molde. Na etapa de acabamento, ocorre a quebra desses canais ou massalotes, que não fazem parte da peça e, portanto, são classificados como sucata. Para isso, a peça é posicionada em local adequado para, então, quebrar manualmente, com marreta e martelo, os canais ou massalotes ${ }^{7}$.

Esse impacto de muita força e de baixa velocidade, através de marretadas manuais, utilizadas ainda hoje (embora já exista tecnologia que substitua o trabalho manual), pode levar a quebrar também a peça, causando a inconveniente perda desta.

\footnotetext{
${ }^{4}$ WORLD HEALTH ORGANIZATION. Basic Documents, Forty-fifth edition, Supplement, October 2006. Disponível em: <file:///C:/Users/D\%C3\%A9bora\%20Martins/Downloads/who_constitution_en.pdf>. Acesso em: 10 maio 2014.

${ }^{5}$ CHEGATTI, S. op. cit.

${ }^{6}$ Id. Ibid.

${ }^{7}$ Id. Ibid.
} 
Além disso, os impactos com as marretas manuais causam cansaço físico extremo ao trabalhador e, em alguns casos, lesões decorrentes do esforço repetitivo (LER) e da vibração de mãos e braços.

O martelo é uma das ferramentas mais primitivas já confeccionadas pelo homem, sendo basicamente um amplificador de força que serve para converter o trabalho mecânico em energia cinética e pressão ${ }^{8}$ No movimento que precede cada pancada, certa quantidade de energia cinética é armazenada na cabeça do martelo, igual ao comprimento do movimento com a força de impulso produzida pelos músculos do braço, associada à força da gravidade ${ }^{6}$. Quando o martelo golpeia, sua cabeça é freada pela força oposta, que vem do objeto; esta é igual e oposta à força que a cabeça do instrumento exerce sobre o alvo. Se o objetivo de quebrar o objeto rígido e maciço não for atingido, o trabalhador receberá de forma refletida vibrações e parte do impacto que não foi absorvido pela peça.

A quantidade de energia liberada pelo golpe do martelo é equivalente à metade da sua massa multiplicada pela velocidade ao quadrado, na hora do impacto. Enquanto a energia liberada no alvo multiplica-se linearmente pela massa, aumenta geometricamente com a velocidade. Por isso, os marreteiros elevam o martelo acima de suas cabeças para então descreverem uma trajetória para baixo, somando à força de seus músculos a ação da gravidade, na tentativa de aumentar a velocidade da pancada. Mas os inconvenientes da execução dessa trajetória pelos marreteiros são inúmeros, podendo-se destacar a exaustiva e repetitiva ativação dos músculos do dorso e membros superiores, além da sustentação do peso da ferramenta (podendo ultrapassar 15 quilos); tudo isso, para gerar energia suficiente para que ocorra a quebra de canais ou massalotes.

É interessante observar que, para que ocorra a quebra de canal ou massalote com diâmetro de 120 milímetros (podendo variar conforme o tipo de material e altura do massalote), seria necessário que o marreteiro segurasse e elevasse a uma altura de dois metros uma marreta de 15 quilos. Essa força é suficiente para causar lesões musculares e articulares no trabalhador. Para conseguir energia de impacto acima de três mil joules utiliza-se o levantamento de pesos de ferro de 500 a mil e quinhentos quilos, que são lançados em queda livre de uma altura de cerca de seis a 10 metros para produzir a energia necessária para a quebra. Em algumas situações utiliza-se esse peso com movimento pendular até atingir energia cinética suficiente para quebrar o massalote quando o choque entre eles ocorrer. É necessário ressaltar que, além dos danos à máquina de levantamento (ponte rolante), existe ainda um risco potencializado de acidentes de trabalho.

${ }^{8}$ WIKIPEDIA a enciplopédia livre. Disponível em <http://pt.wikipedia.org/wiki/Martelo>. Acesso em: 16 de mar. 2012. 
Esses fatos são corroborados por uma pesquisa que analisou os riscos ergonômicos da atividade de 12 marreteiros em uma mineração após observação das tarefas e posturas desses durante as suas jornadas de trabalho de oito horas diárias. A análise postural foi realizada utilizando o software WinOWAS. Segundo esta pesquisa o cansaço físico e a fadiga muscular acometem os marreteiros diariamente ao final de sua jornada de trabalho e ainda $84 \%$ sentiram alguma dor nos membros superiores, o que demonstra que a atividade do marreteiro exige grande esforço físico, expondo-os a riscos ergonômicos e possíveis distúrbios osteomusculares relacionados ao trabalho (DORT) ${ }^{9}$. Além disso, somados aos riscos normais de acidentes inerentes à profissão, os marreteiros estão expostos à poeira, ruído, vibração e fadiga muscular ${ }^{8}$.

A difusão do conhecimento da ergonomia aplicada ao trabalho ganhou visibilidade a partir da década de 1980, quando surgiram os primeiros diagnósticos de Lesões por Esforços Repetitivos/Distúrbios Osteomusculares Relacionados ao Trabalho (LER/DORT). Em decorrência disso, em 1990, foi publicada uma norma específica para regular a aplicação da ergonomia ao trabalho, assim como a sua fiscalização ${ }^{10}$. O problema das LER/DORTs permeia todos os setores da economia e as análises e aplicações de métodos ergonômicos se difundiram como prática, levando muitas empresas a adotar soluções mais racionais e humano-centradas ${ }^{2}$.

O fator "vibração", principalmente sobre as mãos, também tem sido atenuado na sua adversidade à saúde dos trabalhadores. A OMS e o Ministério da Saúde do Brasil ${ }^{11}$ consideram as vibrações como agentes de risco de natureza ocupacional e, o Ministério da Saúde não determina limites de tolerância para as vibrações ocupacionais. Segundo a lista de doenças relacionadas ao trabalho (elaborada em cumprimento à Lei Federal 8.080/199012) a vibração é fator de risco para afecções dos músculos, tendões, ossos, articulações, vasos sanguíneos periféricos ou dos nervos periféricos, e diversas doenças podem ser desenvolvidas tendo na vibração um agente etiológico ${ }^{13}$.

\footnotetext{
${ }^{9}$ PINTO, Norma de Melo; XAVIER, A. A. P; COELHO JÚNIOR, Thalmo de Paiva. Análise dos riscos ergonômicos da atividade do marteleteiro em uma mineração de granito na cidade de baixo guandu no Espírito Santo por meio do software winowas. In: SIMPEP, 13. Bauru, SP, Brasil, 06-08 nov. 2006.

${ }^{10}$ BRASIL. Ministério do Trabalho e Emprego. Portaria MTPS n 3.751, de 23 de novembro de 1990. 17.1. Esta Norma Regulamentadora visa a estabelecer parâmetros que permitam a adaptação das condições de trabalho às características psicofisiológicas dos trabalhadores, de modo a proporcionar um máximo de conforto, segurança e desempenho eficiente. Disponível em: <http://portal.mte.gov.br/data/files/FF8080812BE914E6012BEFBAD7064803/nr_17.pdf>. Acesso em: 15 maio 2014.

${ }^{11}$ BRASIL. Ministério da Saúde. Portaria GM n ${ }^{\circ}$ 1339, de 18 de novembro de 1999. Disponível em: <http://dtr2001.saude.gov.br/sas/PORTARIAS/Port99/GM/GM-1339.html>. Acesso em: 15 maio 2014.

${ }^{12}$ “Art. $6^{\circ}, \S 3^{\circ},(\ldots)$ VII - revisão periódica da listagem oficial de doenças originadas no processo de trabalho, tendo na sua elaboração a colaboração das entidades sindicais;".. BRASIL. Lei n 8.080, de 19 de setembro de 1990. Dispõe sobre as condições para a promoção, proteção e recuperação da saúde, a organização e o funcionamento dos serviços correspondentes e dá outras providências. Disponível em: <http:// www.planalto.gov.br/ccivil_03/leis//8080.htm>. Acesso em: 15 maio 2014.

${ }^{13}$ SEBASTIÃO, B.A.; MARZIALE, M.H.P. A vibração como um fator de risco para a saúde ocupacional. Cien. Cuid. Saúde, v. 7, n. 3, p. 385-391, jul./set. 2008.
} 
A intensidade da vibração recebida por trabalhadores pode ter consequências irreversíveis e a desordem é geralmente progressiva com o aumento da exposição à vibração. Essa exposição pode trazer consequências nas mãos e braços de trabalhadores durante sua vida, tais como diminuição da perfusão, intolerância ao frio, parestesia, enfermidade e inabilidade para manusear objetos pequenos, rigidez nos dedos, redução da força de preensão palmar, dor e fadiga ${ }^{14}$.

Outro agente físico de grande importância é o ruído, presente principalmente nas indústrias, por causar o dano auditivo irreversível ${ }^{9}$. A exposição a elevados níveis de ruído pode acarretar ao trabalhador alterações importantes que interferem na sua qualidade de vida, como a surdez; a interferência nas comunicações pela fala; a não percepção de outras comunicações sonoras; as perturbações do sono; a interferência na atenção e na vigilância no trabalho mental; a redução da privacidade; as modificações de humor; a perturbação do relaxamento mental'.

Nas palavras de Dejours ${ }^{15}$ : "o trabalho nunca é neutro [...] Ou joga a favor da saúde ou, pelo contrário, contribui para a desestabilização e empurra o sujeito para descompensação".

Os níveis de qualidade de vida insatisfatórios atingem parcela significativa da população, dentre esta os que trabalham na função de marreteiro. Há elementos que possibilitem pensar um amanhã diferente ou muito melhor, quais sejam, a substituição de funções prejudiciais à saúde por máquinas. ${ }^{16}$ Esses marreteiros podem ser absorvidos por outras atividades, bem menos danosas à saúde, na própria área de fundição.

O martelo pneumático de impacto é uma importante opção para se quebrarem os pedaços indesejáveis das peças fabricadas em fundição, pois, além de ser um serviço rápido, não há a necessidade do trabalho braçal e danoso à saúde dos marreteiros. Além disso, o martelo pneumático apresenta um guidão, similar a um guidão de bicicleta, o qual o trabalhador segura para posicionar esse equipamento (mirar) no alvo (peça) a ser quebrado. Esse guidão é o elemento de contato entre o martelo e o homem e nele estão acoplados molas e amortecedores, impedindo que a vibração do equipamento seja transmitida ao trabalhador, prevenindo dessa forma os desconfortos causados pelas vibrações de mão e braço ou até mesmo vibração de corpo inteiro.

A substituição do trabalho braçal dos marreteiros foca a resolução de problemas de natureza ergonômica, prevenindo a ocorrência de doenças relacionadas ao trabalho e, ao mesmo tempo, garantindo melhor produtividade às empresas de fundição.

\footnotetext{
${ }^{14}$ SEBASTIÃO, B.A.; MARZIALE, M.H.P. op. cit. ${ }^{15}$ DEJOURS, Chistophe. Da psicopatia à psicodinâmica do trabalho. Rio de Janeiro: Ed. Fiocruz, 2004. p. 138.

${ }^{16}$ VILARTA, R.; GUTIERREZ, G.L.; CARVALHO, T.H.P.F; GONÇALVES, A (Orgs.). op. cit.
} 
E, não só isso, esse trabalho, nas condições apresentadas, traz na sua tônica a deterioração das condições psíquicas e o desequilíbrio emocional do trabalhador. O trabalho humano traz em si um sentido e que muitas vezes pode ser do gozo ou do sofrimento, pois, diz Antunes": "É essa contraditória processualidade do trabalho que emancipa e aliena, humaniza e sujeita, libera e escraviza”. O referido médico psicanalista e ergonomista francês, na análise dos sinais diretos de medo e suas implicâncias psíquicas do trabalhador, assim considera:

A ordem jurídica brasileira fundada nos princípios constitucionais, especialmente no valor social do trabalho e da dignidade humana, e outros parâmetros legais constitucionais, conforme demonstrados a seguir, não coaduna com a possibilidade desse tipo de trabalho no Brasil. Nesse diapasão, um trabalho onde o cidadão deve carregar o equivalente a $15.000 \mathrm{~kg}$ por dia, martelando pedaços de peças fundidas, em condições desumanas, deve ser abolido. Ainda mais conhecendo possibilidades de máquinas pneumáticas que fazem esse trabalho de modo mais rápido, eficaz e sem nocividade ao homem ${ }^{18}$.

\section{Trabalho do marreteiro: uma análise sob o aspecto jurídico}

O valor da pessoa é um princípio fundamental da ordem jurídica brasileira, demonstrando assim a necessidade de se observar que todo o ordenamento deve se voltar para o epicentro - homem - garantindo a proteção de sua plenitude e integridade, espargindo seus efeitos nas esferas individual, econômica e social, constituindo verdadeiro parâmetro obrigatório para qualquer contexto em análise. Nesse sentido, manifesta Gabriela Neves Delgado e conclui: "portanto, o princípio da pessoa humana traduz, na Constituição Federal de 1988, a ideia de que o valor central da sociedade está na pessoa, centro convergente dos direitos fundamentais".

O texto da Constituição da República Federativa do Brasil de 1988 (CR/88), em seu artigo $7^{\circ}$, inciso XXIII ${ }^{19}$, dispõe sobre o adicional por trabalho penoso. Todavia, passados 24 anos da promulgação da CR/88, não há qualquer regulamentação infraconstitucional acerca do tema.

\footnotetext{
${ }^{17}$ ANTUNES, Ricardo. Os sentidos do trabalho: ensaio sobre a afirmação e negação do trabalho. 2. ed. 10 reimpr. rev e ampl. São Paulo: Boitempo, 2009. p. 12.

18“A propósito deste discurso trabalhador sobre a saúde física, é muito comum se colocar a ênfase analítica no que está mais imediatamente expresso, ou seja, de que as condições de trabalho são prejudiciais para o corpo. Mesmo sendo incontestável tal realidade, negligenciamos em geral a própria palavra, o momento em que é pronunciada e o tom no qual se expressa. Ora, esta palavra é uma palavra carregada de ansiedade. Se a relação corpo-condições de trabalho muitas vezes é estudada corretamente, ao contrário, nunca se faz menção das repercussões do perigo real a nível mental, da carga (de trabalho) psíquica inerente ao trabalho perigoso que, entretanto, faz parte do desgaste do organismo astreinte." DEJOURS, Christophe. A loucura do trabalho: estudo de psicopatologia do trabaIho. 5. ed. ampl. São Paulo: Cortez-Oboré, 1992. p. 66.

19،“Art. $7^{\circ}$ (...) XXIII - adicional de remuneração para as atividades penosas, insalubres ou perigosas, na forma da lei;". BRASIL. Constituição da República Federativa do Brasil de 1988. Disponível em: <http://www. planalto.gov.br/ccivil_03/constituicao/constituicaocompilado.htm> Acesso em: 15 maio 2014.
} 
Nessa toada, ensina Daniela Muradas Reis que restaria claro que "os direitos dos trabalhadores são dimensão dos direitos humanos, enfeixando garantias pertinentes à pessoa humana na sua face econômica e social"20.

Ainda, importante avaliar que a texto constitucional traz também parâmetro essencial, princípio e fundamento: o valor social do trabalho. Assim, não só a observância da dignidade do ser humano, mas prestigiar o valor que o trabalho traz em si e a necessidade de uma efetiva proteção constituem deveres do Estado e da sociedade, insculpidos na ordem jurídica máxima: a Constituição.

Ora, como salientado, o trabalho traz em si um sentido para o homem, sentido esse que o estrutura como indivíduo e é significativo para estabelecer sua identidade, ampliando para o espectro social coletivo. Também é um valor para a sociedade que faz emanar a necessidade de larga proteção, especialmente se observarmos que o homem éo cerne do sistema. Conforme Gabriela Neves Delgado ressalta, a dignidade e o trabalho são direitos fundamentais do homem, e o direito fundamental ao trabalho digno se constitui em parâmetro necessário ao verdadeiro conceito de Estado Democrático de Direito.

O trabalho humano digno, de significado estruturante para o homem, não interessa à lógica perversa do sistema capitalista de acumulação ultraliberal que insiste em apor o lucro como cerne do sistema jurídico e social. Não é à toa que a sociedade pós-moderna padece mais e mais da sua doença em estágio quase terminal: a grave injustiça social gerada pela má distribuição de renda e a não observância de parâmetros geradores de trabalho digno e da sua manutenção.

Ainda, a exploração do trabalho como gerador de condições inadequadas e nocivas aos trabalhadores, resultando na degradação de sua saúde, também deteriora o meio ambiente do trabalho. Conforme a CR/88, a ordem econômica encontra como barreira o valor social do trabalho, a dignidade humana, como ainda o dever de zelar pelo meio ambiente, inclusive o do trabalho.

O adicional por trabalho penoso é medida para tentar minimizar os efeitos daquele que trabalha em condições mais gravosas, já que a percepção de adicionais por um empregado é devida em circunstâncias tipificadas mais gravosas, conforme salienta Maurício Godinho Delgado ${ }^{21}$.

Ocorre, porém, que independentemente da discussão doutrinária em torno do que seja trabalho penoso e da ausência de regulamentação jurídica infraconstitucional que possibilite eliminar ou indenizar, há de se considerar o sentido desestruturante desse trabalho e a grave afronta aos princípios basilares da dignidade da pessoa humana e do valor social do trabalho, ambos como limite às relações e à exploração da atividade econômica no país.

\footnotetext{
${ }^{20}$ REIS, Daniela Muradas. O princípio da vedação do retrocesso no direito do trabalho. São Paulo: LTr, 2012. p. 153.

${ }^{21}$ DELGADO, Maurício Godinho. Curso de direito do trabalho. 11. ed. São Paulo: LTr, 2012. p. 759.
} 
Ademais, em face do desgaste e da agressividade do trabalho aqui relatado, não há que se falar em um adicional para minimizar efeitos. Na realidade, o tipo de trabalho primitivo e nocivo dos marreteiros, na forma demonstrada, deve ser banido da sociedade, por representar algo além: trata-se de afronta à saúde do trabalhador e de ofensa ao padrão de dignidade humana, desconstituindo o valor social que o trabalho possui. Assim, saúde, dignidade e o próprio valor do trabalho, protegidos pela ordem jurídica nacional, bem como por convenções, recomendações e manuais da Organização Internacional do Trabalho (OIT), restam desrespeitados.

Um dos fundamentos do Estado brasileiro, disposto no artigo $1^{\circ}$ da $\mathrm{CR} / 88^{22}$, trata da dignidade da pessoa humana. Esse princípio visa tutelar uma vida digna de todas as pessoas, inclusive no que diz respeito aos fatores econômicos, dentre eles, o trabalho.

A Constituição determina através do seu artigo 170 que a ordem econômica, que tem como um dos fundamentos o valor social do trabalho, deve garantir uma existência digna, limitando a atividade, entre outros parâmetros, ao dever de preservação do meio ambiente, com clara submissão da propriedade à sua função socioambiental.

Resta clara no texto constitucional brasileiro a submissão da propriedade à sua função socioambiental, em contramão ao ideário neoliberal e da perversa lógica do capital: a acumulação e a injustiça social. Ensina Maurício Godinho Delgado ${ }^{23}$ acerca do princípio da submissão da propriedade à função socioambiental.

Notadamente o exercício da atividade econômica está condicionado à proteção do meio ambiente. $\mathrm{O}$ artigo 225 da Constituição tutela o meio ambiente como um todo, e o artigo 200 demonstra claramente que o meio ambiente do trabalho está intrínseco ao conceito amplo de meio ambiente ${ }^{24}$.

Resta, portanto, inequívoca a obrigatoriedade da observância pelos atores sociais dos parâmetros de dignidade da pessoa humana, do valor social do trabalho

\footnotetext{
22“Art. $1^{\circ}$ A República Federativa do Brasil, formada pela união indissolúvel dos Estados e Municípios e do Distrito Federal, constitui-se em Estado Democrático de Direito e tem como fundamentos: (...) III - a dignidade da pessoa humana;". BRASIL. Constituição da República Federativa do Brasil de 1988. Disponível em: <http:// www.planalto.gov.br/ccivil_03/constituicao/constituicaocompilado.htm> Acesso em: 15 maio 2014.

23“"A submissão da propriedade à sua função socioambiental ao mesmo tempo em que afirma o regime da livre iniciativa, enquadra-o rigorosamente, em leito de práticas e destinações afirmatórias do ser humano e dos valores sociais e ambientais. É inconstitucional para a Carta Máxima, a antítese, 'o lucro ou as pessoas'; a livre iniciativa e o lucro constitucionalmente reconhecidos - e, nessa medida, protegidos - são aqueles que agreguem valor aos seres humanos à convivência e aos valores da sociedade, à higidez do meio ambiente geral, inclusive o do trabalho." DELGADO. Maurício Godinho. Os princípios do direito de direito individual e coletivo do trabalho. 2. ed. São Paulo: LTr, 2004. p. 38-39.

${ }^{24}$ [....] envolve quatro significativos aspectos que são: natural, cultural, artificial e do trabalho, e assim podemos descrever várias espécies de meio ambiente que podem ser mencionados da seguinte forma: meio ambiente artificial (prédios, ruas e áreas urbanas); meio ambiente cultural e patrimônio artístico e arqueológico (histórico de uma sociedade); meio ambiente do trabalho (o local onde se desenvolve a atividade profissional)." ARAÚJO, Gisele Ferreira. Meio ambiente do trabalho: aspectos teóricos. In: DARCANCHY, Mara Vidigal (Coord.) Responsabilidade social nas relações laborais. São Paulo: LTr, 2007. p. 142-164.
} 
e de um meio ambiente do trabalho saudável, traduzido em segurança do trabalhador, saúde física e psicológica, e salvaguarda do valor e significado estruturante do trabalho na vida do homem ${ }^{25}$.

Observando os princípios e fundamentos aqui destacados, é possível então concluir que, através da $\mathrm{CR} / 88$, o homem está na centralidade do sistema e, por conseguinte, a atividade humana por excelência - $\mathrm{o}$ trabalho -, pelo seu significado, pelo seu valor, pelo seu sentido, uma vez "que trabalho é meio de vida e não de morte" ${ }^{26}$. $\mathrm{O}$ trabalho é atribuir àquilo que é da essência humana o seu verdadeiro valor.

Nesse diapasão, cristalino é que o trabalho do marreteiro, por seu contexto de sofrimento, configurado como trabalho em condições subumanas, não pode ser permitido. Não só a ordem constitucional como também mecanismos de tutela internacional do trabalho não coadunam com tal atrocidade. Deixar que homens sejam submetidos a situação tão degradante somente atende à voracidade do capital, não havendo outra lógica que explique.

Não pretende o presente estudo aprofundar na seara do direito internacional do trabalho; mas, apenas para corroborar a tese aqui defendida, ainda salienta alguns tópicos a fim de demonstrar que parâmetros internacionais são também desrespeitados.

A OIT defende ao longo de sua existência formas dignas de trabalho, sempre com a promoção, defesa e conscientização do valor do trabalho, e da dignidade do trabalhador. No curso de sua história, com mais de sete décadas, inúmeras foram as convenções que categorizaram os direitos dos trabalhadores ao patamar de direitos humanos.

A referida organização destaca que, em 1998, aprovou a Declaração Relativa aos Direitos Fundamentais do Trabalho, reafirmando assim o valor do trabalho e a dignidade que lhe é inerente, bem como as diretrizes da Convenção de Filadélfia e da Constituição da OIT. Por esse instrumento "reiterou o reconhecimento do valor ínsito ao trabalho humano no plano internacional, reafirmando os marcos jurídicos civilizatórios da relação entre capital e trabalho"27. A partir de então, especificamente de 1999 em diante, a OIT vem promovendo a busca do "trabalho decente" 28.

\footnotetext{
25“No caso do meio ambiente, o que se preserva é o acesso de todos à qualidade de vida, cuidando para que a saúde corporal e mental não seja atingida por agressões ambientais decorrentes do desenvolvimento de tecnologia, dos processos e necessidades produtivas, dos maquinismos e da explosão urbana. [...] 0 Meio ambiente do trabalho não se define apenas como o conjunto das condições, leis, influências e integrações de ordem física, química e biológica, mas está aliado aos fatores pessoais e suas limitações de ordem individual, fatores psicológicos, ergonômicos e de acidentes." ARAÚJO, Gisele Ferreira. op. cit., p. 142-164. ${ }^{26}$ ARAUJO, op. cit. 2012

${ }^{27}$ REIS, Daniela Muradas. op. cit., p. 99.

28“O Trabalho Decente é o ponto de convergência dos quatro objetivos estratégicos da OIT: o respeito aos direitos no trabalho (em especial aqueles definidos como fundamentais pela Declaração Relativa aos Direitos e Princípios Fundamentais no Trabalho e seu seguimento adotada em 1998: (i) liberdade sindical e reconhecimento efetivo do direito de negociação coletiva; (ii )eliminação de todas as formas de trabalho forçado; (iii) abolição efetiva do trabalho infantil; (iv) eliminação de todas as formas de discriminação em matéria de emprego e ocupação), a promoção do emprego produtivo e de qualidade, a extensão da proteção social e o fortalecimento do diálogo social.". ORGANIZAÇÃO INTERNACIONAL DO TRABALHO. O que é o Trabalho Decente. Disponível em: <http://www.oit.org.br/content/o-que-e-trabalho-decente>. Acesso em: 15 maio 2014.
} 
Note-se, então, que no Brasil a agenda do trabalho decente foi formalizada, por decreto presidencial, instituindo o Plano Nacional de Emprego e Trabalho Decente (PNETD) em 2009.

Nesse sentido, ao cotejo do trabalho arcaico aqui analisado e do comando subjacente à extensa obra normativa da OIT - aqui pinçados apenas alguns detalhes para efeito de exemplo -, já é possível inferir o abuso e a afronta aos direitos fundamentais do trabalho.

Daniela Muradas Reis afirma que, uma vez alcançada a salvaguarda de patamares de preservação de direitos humanos, não caberia, portanto, "retrocesso sociojurídico", e a análise do princípio da progressão social do trabalhador formula a "reserva implícita ao retrocesso sociojurídico do trabalhador"

No cotejo da ampla garantia de direitos constitucionais como a dignidade da pessoa humana e o valor social do trabalho, bem como da proteção ao meio ambiente do trabalho, além dos direitos fundamentais dos trabalhadores insculpidos nas convenções e recomendações da OIT que visam ao trabalho decente, permitir um trabalho forçoso, desgastante, penoso, gerador de sofrimento físico e psíquico, em modelo primitivo, é permitir um retrocesso nos direitos fundamentais do homem.

\section{0 martelo pneumático como proposta de substituição do processo de trabalho do marreteiro}

Atualmente a quebra de massalotes também pode ser realizada por meio da lixadeira de corte (corte com maçarico) ou por meio do pêndulo. No primeiro caso, o custo e o tempo gasto para efetuar a quebra dos massalotes são elevadíssimos e por isso não é a técnica de escolha. No segundo, um pêndulo com cerca de 700 quilos é içado a uma ponte rolante e balançado até que atinja o alvo. Também não é a técnica mais adequada, pois, além de ser extremamente perigosa, é pouco precisa e de alto custo por danificar a ponte rolante.

Mas existe, no mercado, a opção do martelo pneumático de impacto, que proporciona a resolução de problemas de natureza ergonômica, prevenindo a ocorrência de doenças relacionadas ao trabalho, enquanto também garante melhor e maior produtividade para as empresas.

Essa tecnologia é um equipamento totalmente pneumático ligado à pressão normal de uma rede de ar comprimido industrial ( 6 bar - unidade de pressão) por meio de mangueira. Para sua utilização, ele deve ser içado por um equipamento de levantamento disponível e guiado pelo marreteiro, que, agora, irá apenas posicioná-lo diretamente no massalote a ser quebrado e, por uma botoeira, acioná-lo.

${ }^{29}$ REIS, Daniela Muradas. op. cit., p. 126. 
A relação entre o peso da marreta e a potência gerada para quebrar peças de diferentes diâmetros está apresentada na Tabela 1 .

Nesse aspecto, a tecnologia, que tantas vezes deteriora o ambiente de trabalho e é fator de precarização de direitos, pode ser uma solução a evitar todo o desgaste e seus perversos reflexos, já relatados.

Tabela 1. Comparação entre martelo pneumático e marreta manual

\begin{tabular}{lccc}
\hline $\begin{array}{l}\text { Modelo do martelo } \\
\text { pneumático }\end{array}$ & $\begin{array}{c}\text { Peso da Marreta } \\
(\mathrm{Kg})\end{array}$ & $\begin{array}{c}\text { Energia Impacto } \\
\text { (Joule) }\end{array}$ & $\begin{array}{c}\text { Diâmetro da peça a } \\
\text { ser quebrada }(\mathrm{mm})\end{array}$ \\
\hline V200 & 1,5 & 200 & 15 \\
V400 & 2 & 400 & 26 \\
V600 & 3,5 & 600 & 30 \\
V1000 & $5 / 6$ & 1.000 & 45 \\
V1200 & 7 & 1.200 & 60 \\
V1800 & $8 / 9$ & 1.800 & $75 / 80$ \\
V2000 & $10 / 13$ & 2.000 & $90 / 100$ \\
V3000 & $15 / 18$ & 3.000 & $120 / 130$ \\
V9000 & - & 9.000 & $180 / 200$ \\
V17000 & - & 17.000 & 250 \\
V30000 & - & 30.000 & 300 \\
\hline
\end{tabular}

Fonte: Manual técnico do martelo pneumático ${ }^{30}$.

\section{Considerações finais}

Muitos são os danos a que o marreteiro está suscetível e incluem riscos ergonômicos, tais como doenças por esforço repetitivo; mutilações; e doenças psicossomáticas, devido às condições de trabalho, em especial ao ruído, fadiga muscular cansaço físico e ao estresse.

A proteção ao trabalho, fundamentada em diversos dispositivos constitucionais, resguarda o trabalhador, em princípios personificados na cidadania, dignidade da pessoa humana e valores sociais do trabalho. Esses direitos devem ser observados no sentido de evitar funções degradantes e nocivas, em especial quando se têm alternativas acessíveis.

Pelo exposto, deve a sociedade alertar para os riscos à pessoa humana e buscar alternativas para melhorar as condições de trabalho dos marreteiros, bem como para amenizar os riscos de danos à saúde desses trabalhadores.

\footnotetext{
${ }^{30}$ VOLPI. Manual técnico do martelo pneumático. 2011.
} 
O martelo pneumático de impacto é uma importante solução para se quebrarem os pedaços indesejáveis das peças fabricadas em fundição, pois, além de um serviço rápido, não há a necessidade do trabalho braçal e danoso à saúde dos marreteiros.

Em tempos de alta tecnologia, em que é possível localizar um trabalhador em qualquer local que ele esteja e auferir a sua produção, em que pessoas ficam plugadas aos seus aparelhos tecnológicos promovendo o acesso em tempo real aos fatos, tempos em que muitos já não sabem mais como é relacionar presencialmente, o trabalho com um martelo, em ritmo exaustivo e sofrido, mais parece algo de ficção científica às avessas. O primitivo hoje é o virtual, ou seja, algo que estaria somente nas lembranças e no imaginário humano.

Os avanços tecnológicos, que muitas vezes atendem às demandas do grande capital, desta vez não foram implementados, pois na mesma medida a falta de tecnologia também socorre, neste caso, à ganância da acumulação forjada pelo sofrimento humano.

Um estudo em campo mais aprofundado pode enriquecer as discussões acerca do trabalho dos marreteiros e de suas repercussões na saúde desses trabalhadores. A partir disso faz-se necessária a adoção de medidas de proteção coletiva e modificações em equipamentos e em processos de produção, encorajando a busca por melhores condições de trabalho e consequente aumento da qualidade de vida dos funcionários desse setor.

\section{Referências}

ANDRADE, Mam; GOSLING, M.; XAVIER, W. S. Por trás do discurso socialmente responsável da siderurgia mineira. Produção, v. 20, n. 3, p. 418-428, 2010.

ANTUNES, Ricardo. Os sentidos do trabalho: ensaio sobre a afirmação e negação do trabalho. 2. ed. 10 reimpr. rev e ampl. São Paulo: Boitempo, 2009.

ARAÚJO, Gisele Ferreira. Meio ambiente do trabalho: aspectos teóricos. In: DARCANCHY, Mara Vidigal (Coord.) Responsabilidade social nas relações laborais. São Paulo: LTr, 2007.

BASTOS, Celso. Curso de direito constitucional. São Paulo: Saraiva, 2009.

CHEGATTI, S. Aplicação de resíduos de fundição em massa asfáltica cerâmica vermelha e fritas cerâmicas. 2004. Dissertação (Mestrado em Engenharia Ambiental) - Universidade Federal de Santa Catarina, Florianópolis, 2004.

DEJOURS, Christophe. Da psicopatia à psicodinâmica do trabalho. Rio de Janeiro: Ed. Fiocruz, 2004.

A loucura do trabalho: estudo de psicopatologia do trabalho. 5. ed ampl. São Paulo: Cortez-Oboré, 1992.

DELGADO, Gabriela Neves. Direito fundamental ao trabalho digno. São Paulo: LTr, 2006. 
DELGADO, Maurício Godinho. Curso de direito do trabalho. 11. ed. São Paulo: LTr, 2012. . Os princípios do direito de direito individual e coletivo do trabalho. 2. ed. São Paulo: LTr, 2004.

FAGUNDES, A. B. Mapeamento do gerenciamento das areias a verde de fundição no Estado do Paraná sob a ótica da produção mais limpa: uma contribuição para o estabelecimento de estratégias. 2010. Dissertação. (Mestrado em Engenharia de Produção) - UTFPR, Ponta Grossa, 2010.

LAFRATTA, F.H.; SANTOS, G.A. dos; LEMOS, R. J.; FRANÇA, A. G. Melhoria do ambiente de trabalho em empresas de fundição do pólo metal-mecânico da região de Joinville. In: ENCONTRO DE EXTENSÃO DA UDESC, 6. Joinville, 19-20 Maio 2011.

ORGANIZAÇÃO INTERNACIONAL DO TRABALHO. O que éo Trabalho Decente. Disponível em: < http://www.oit.org.br/content/o-que-e-trabalho-decente >. Acesso em: 15 maio 2014.

PINTO, Norma de Melo; XAVIER, A. A. P; COELHO JÚNIOR, Thalmo de Paiva. Análise dos riscos ergonômicos da atividade do marteleteiro em uma mineração de granito na cidade de baixo guandu no Espírito Santo por meio do software winowas. In: SIMPEP, 13. Bauru, SP, Brasil, 06-08 nov. 2006.

REIS, Daniela Muradas. O princípio da vedação do retrocesso no direito do trabalho. São Paulo: LTr, 2012.

SEBASTIÃO, B.A.; MARZIALE, M.H.P. A vibração como um fator de risco para a saúde ocupacional. Cien. Cuid. Saúde, v. 7, n. 3, p. 385-391, jul./set. 2008.

SILVA, Thais Cláudia D'Afonseca. A responsabilidade social empresarial: uma análise sob a ótica do direito do trabalho. 2008. Dissertação (Mestrado). 113 f. Disponível em: <http:// www.biblioteca.pucminas.br/teses/Direito_SilvaTC>. Acesso em: 27 nov. 2012.

VILARTA, R.; GUTIERREZ, G.L.; CARVALHO, T.H.P.F; GONÇALVES, A (Orgs.). Qualidade de vida e novas tecnologias. Campinas: Ipes Editorial, 2007.

VOLPI. Manual técnico do martelo pneumático. 2011.

WIKIPEDIA a enciplopédia livre. Disponível em <http://pt.wikipedia.org/wiki/Martelo $>$. Acesso em: 16 de mar. 2012.

WORLD HEALTH ORGANIZATION. Basic Documents, Forty-fifth edition, Supplement, October 2006. Disponível em: < file://C:/Users/D\%C3\%A9bora\%20Martins/Downloads/ who_constitution_en.pdf $>$. Acesso em: 10 maio 2014. 
Silva C. R. V., Lana M. R. V., Silva T. C. D.

Carla Ribeiro Volpini Silva - Doutora em Direito Público pela Pontifícia Universidade Católica de Minas Gerais; Mestre em Direito Internacional e Comunitário pela Pontifícia Universidade Católica de Minas Gerais. Professora adjunta da Faculdade de Direito da Universidade Federal de Minas Gerais; Professora da Universidade de Itaúna. Belo Horizonte/MG, Brasil. E-mail: carlavolpini@hotmail.com.

Mariana Ribeiro Volpini Lana - Doutoranda em Engenharia Mecânica pela Universidade Federal de Minas Gerais; Mestre em Engenharia Mecânica pela Universidade Federal de Minas Gerais; Pós-Graduada em Fisioterapia Neurológica pela Faculdade de Ciências Médicas de Minas Gerais. Professora da Faculdade Estácio de Sá de Belo Horizonte. Supervisora Técnica da Oficina de Órteses da Associação Mineira de Reabilitação. Fisioterapeuta. Belo Horizonte/MG. Brasil.E-mail: marivolpini@yahoo.com.br.

Thaís Cláudia D’Afonseca da Silva - Mestre em Direito do Trabalho pela Pontifícia Universidade Católica de Minas Gerais. Professora da Escola Superior Dom Helder Câmara. Advogada especializada na área trabalhista. Membro da banca da $2^{\text {a }}$ fase do XII Exame Unificado da OAB. Belo Horizonte/MG, Brasil. E-mail: thais@thaisclaudia.com.br. 